Original Research Article

\title{
Pharmacovigilance in cancer chemotherapy in regional cancer center of Eastern India: prospective observational study
}

\author{
Anima Rout ${ }^{1}$, Rajendra K. Panda ${ }^{1 *}$, Vedvyas Mishra ${ }^{1}$, Prasant Parida ${ }^{2}$, Srikant Mohanty ${ }^{1}$
}

${ }^{1}$ Department of Pharmacolody, S.C.B. Medical College, Cuttack, Odisha, India ${ }^{2}$ Department of Oncology, Achraya Harihar Regional Caner Centre, Cuttack, Odisha, India

Received: 27 June 2017 Accepted: 03 July 2017

\section{*Correspondence to: \\ Dr. Rajendra K. Panda, Email: drrajendrapanda@ gmail.com}

Copyright: (C) the author(s), publisher and licensee Medip Academy. This is an openaccess article distributed under the terms of the Creative Commons Attribution NonCommercial License, which permits unrestricted noncommercial use, distribution, and reproduction in any medium, provided the original work is properly cited.

\begin{abstract}
Background: Globally cancer is the leading cause of morbidity and mortality with annual death rate of $12 \%$. According Indian Council of Medical Research, more than 1300 Indians die every day due to cancer. Chemotherapy is one of the multimodal approaches for treatment of cancer and regimens are much complex and cancer patients are more susceptible to adverse drug reaction with little tolerance due to diminished immunity. The present study was done to evaluate the prevalence of various adverse drug reactions with different cancer chemotherapy regimens, their nature and severity as well as their causality assessment as per WHO scale.

Methods: This prospective observational study was conducted from July 2015 to June 2016. Patients receiving cancer chemotherapy from regional cancer centre, Cuttack were observed during the study period for the adverse drug reactions. Those ADRs were analysed for causality assessment, severity and preventability. Results: It was observed that after the initiation of chemotherapy, ADRs were observed in $92(88.46 \%)$ patients. Among these 329 observed ADRs, during the study period, female predominance was observed in the age group 51-60yrs. Most common ADRs observed were nausea and vomiting 57 (17.37\%), alopecia 46 $(13.98 \%)$ and neutropenia $38(11.55 \%)$. ADRs were most commonly seen with the haematological systems $(37.68 \%)$ followed by gastrointestinal system amounting $25.22 \%$ of the total ADRs. Platinum Compound (58.35\%), followed by antibiotics, antimetabolites, were the most common group of drugs causing different adverse drug reactions. On causality assessment, as per WHO-UMC criteria $68.38 \%$ were probable and $31.62 \%$ ADRs were possible. Severity assessment showed majority of the ADRs were moderate $228(69.31 \%)$ followed by mild $67(20.36 \%)$ and severe $34(10.33 \%)$. It was observed that majority 212 $(64.45 \%)$ of the ADRs were not preventable, $72(21.88 \%)$ were definitely preventable and $45(13.67 \%)$ were probably preventable.

Conclusions: Cancer chemotherapy has definitely improved the quality of life, but associated ADRs need early diagnosis, prompt management and routine reporting. Thus, pharmacovigilance will definitely reduce morbidity and mortality, so also the financial burden for the patients and society.
\end{abstract}

Keywords: Adverse drug reaction, Anticancerous drugs, Chemotherapy induced, Pharmacovigilance

\section{INTRODUCTION}

Globally cancer is the leading cause of morbidity and mortality with annual death rate of $12 \% .{ }^{1,2}$ According to national cancer registry programme of Indian Council of Medical Research, more than 1300 Indians die every day due to cancer. ${ }^{3}$ Between 2012-2014 the estimated mortality rate due to cancer increased approximately $6 \%$ of the total cancer patients. ${ }^{3}$ Chemotherapy is one of the multimodal approaches for treatment of cancer. ${ }^{4}$ Chemotherapy regimens are much complex and cancer patients are more susceptible to adverse drug reaction with little tolerance due to diminished immunity. ${ }^{4}$ 
As defined by World Health Organisation, adverse drug reaction (ADR) is any noxious or unintended response to a drug, which occurs at doses normally used in man for prophylaxis, diagnosis or therapy of disease, or for modification of physiological function. ${ }^{5}$ ADRs are a major cause of morbidity, hospital admission, increased healthcare expenditure, and even death. ${ }^{6}$ The prevalence of ADRs of anticancer drugs in Indian context is $10-12 \% .^{7}$

World Health Organization defined pharmacovigilance as the science and activities related to the detection, assessment, understanding, and prevention of adverse effects or any drug related problem (WHO, 2002). The information generated by pharmacovigilance is useful in educating doctors about ADRs and to lead steps in regulation of drug use. Its main purpose is to reduce the risk of adverse effects, to reduce suffering and to increase quality of life. Pharmacovigilance studies are highly essential in oncology. Antineoplastic agents are well studied and are extremely beneficial in cancer treatment, but they are used with caution due to their high toxicity and narrow therapeutic window. ${ }^{8}$ ADRs are so common and predictable in oncology that they came around to being accepted as an inevitable component of the treatment. ${ }^{9}$

ADR associated with chemotherapeutic drugs decrease the quality of life, and increases the mortality as well as the healthcare budget. ${ }^{10}$ It has been found that the ADR profile of cancer chemotherapeutics is very less reported and the situation is even worse in India. ${ }^{11}$ In spite of high burden of cancer and adverse drug reactions to antineoplastic drugs, there are few documented data regarding pharmacovigilance from eastern India. The present study was done to evaluate the prevalence of various adverse drug reactions with different cancer chemotherapy regimens, their nature: severity, preventability as well as their causality assessment.

\section{METHODS}

The current study is a prospective observational study done from July 2015 to June 2016. The study was conducted in Department of Pharmacology, SCB Medical College, Cuttack in collaboration with the Medical Oncology Department of Regional cancer Centre, Cuttack known as Acharya Harihar Regional Cancer Centre (AHRCC), which is situated in the S.C.B. Medical campus.

After explaining in detail about the study, written informed consent was obtained from the patients (or their relatives) under study prior to their enrollment. Consent form was prepared as per the ethical guidelines. Patients were selected for the study as per the inclusion and exclusion criteria detailed below.

\section{Inclusion criteria}

All patients aged more than 18 years, who were confirmed cases of cancer and receiving anti-cancer drugs either as single agent or in combination of two or more drugs were included in the study.

\section{Exclusion criteria}

Cancer patient on radiotherapy or planned for surgery and those who were unwilling to participate in the study are excluded from study. Adverse drug reaction due to any other cause like blood transfusion, patients with history of drug abuse, and intoxications were excluded.

\section{Data collection and follow up}

Patients were recruited for the study till December 2015 and all eligible patients were followed up for 4 months after initiation of chemotherapy. After enrollment of the patients in study, data regarding demographic, clinical and treatment details were collected in a specially designed data collection form. Clinical details include diagnosis, baseline vital signs and associated comorbidity at the time of presentation in outpatient department and baseline laboratory investigation included cytopathology, radio imaging and haematological data. Treatment details which include the regimen prescribed, dose of individual drug, frequency and route of administration, date of initiation of chemotherapy were recorded.

All patients were followed up during their subsequent visits and hospital stay. Recording of body temperature, pulse, blood pressure, and other physical examination were done during hospital stay. All the routine investigations were performed at Regional Diagnostic Centre, A.H.R.C.C and reports were analyzed for different parameters of each patient in each cycle.

Adverse drug reactions were noted during their subsequent visit to the hospital. The description of the adverse events and onset and ablation of the same, information on challenge and dechallenge, duration of hospital stay, type of ADRs, system affected by the ADRs, outcome of the ADRs, and drugs used to manage the ADRs were analyzed.

\section{Causality assessment of adverse drug reaction}

The WHO causality assessment scale determines the causal relationship of a suspected drug to the ADR in question and causality is categorized into "certain," "probable," “possible," “unlikely," “conditional/ unclassified" and "unassessable/ unclassifiable."12 The modified Hartwig and Siegel scale classifies severity of ADR as "mild," "moderate, "or "severe" with various levels, depending on factors like requirement for change in treatment, duration of hospital stay and the disability produced by the ADR. ${ }^{13}$ The modified Schumock and Thornton scale determines the preventability of an ADR and classifies them as "definitely preventable", "probably preventable" and "not preventable". ${ }^{14}$ 


\section{Stastical analysis}

The descriptive statistical analysis was performed with the SPSS software package version 24, NY: IBM Corporation and frequencies were determined for each variable.

\section{RESULTS}

It was observed that out of 126 patients enrolled during the study period as per inclusion and exclusion criteria, 104 could be followed up till the end of study. Among these 104 patients, 45 were males and 59 were females which shows male female ratio was 1:1.31. Maximum number $(26.92 \%)$ of patients were in the age group 41-50yrs (Table $1)$.

\section{Table 1: Demographic variation of the study population.}

\begin{tabular}{|llll|}
\hline \multicolumn{2}{|l}{ Variables } & Number & $\begin{array}{l}\text { Percentage } \\
(\mathbf{n}=\mathbf{1 0 4})\end{array}$ \\
\hline \multirow{3}{*}{ Sex } & Male & 45 & $43.26 \%$ \\
\cline { 2 - 4 } & Female & 59 & $57.74 \%$ \\
\hline \multirow{4}{*}{ Age } & $21-30$ years & 20 & $19.2 \%$ \\
\cline { 2 - 4 } & $31-40$ years & 21 & $20.19 \%$ \\
\cline { 2 - 4 } & 41-50 years & 28 & $26.92 \%$ \\
\cline { 2 - 4 } & 51-60 years & 26 & $26 \%$ \\
\cline { 2 - 4 } & 61-70 years & 9 & $9 \%$ \\
\hline
\end{tabular}

Of the total 104 patients included in the study 31(29.8\%) of them suffered from cancer breast which was the highest followed by cancer of stomach in 21 patients. Ovarian cancer, carcinoma of buccal cavity and carcinoma gall bladder were observed in 13,11 and 10 patients respectively. Other cancers included in miscellaneous group were gestational trophoblastic tumour, rhabdomyosarcoma, germ cell tumour of the testis, seminoma of testis, ewing's sarcoma and osteosarcoma (Figure 1).

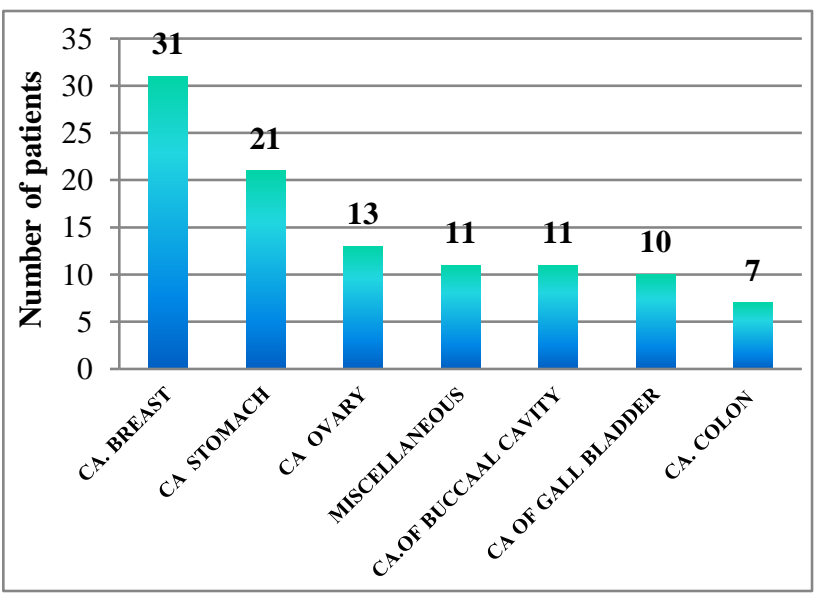

Figure 1: Distribution of different cancers in study population.
Among these 104 cancer patients from different sites as described above, 13 types of regimens were prescribed. Frequently prescribed regimens were TAC (Cyclophosphamide+ Adriamycin+ Paclitaxel), CAPOX (Capecitabine+ Oxaliplatin) and Capoxe FU (Capecitabine+ Oxaliplatin+ Epirubicin+ 5 Flurouracil) which were prescribed in 19,14 and 10 numbers of patients respectively. Least prescribed regimens were FEC (Cyclophosphamide+ Epirubicin+ 5 Flurouracil) and BEP (Bleomycin+ Etoposide+ Cisplatin). Rest all regimens were detailed in Figure 2 and Table 2.

Table 2: ADRs observed with different regimens.

\begin{tabular}{|c|c|c|c|}
\hline Regimens & Drug combination & $\begin{array}{l}\text { ADRs } \\
\text { observed } \\
(\mathbf{n}=329)\end{array}$ & $\%$ \\
\hline $\begin{array}{l}\text { Capoxe } 5 \\
\text { FU }\end{array}$ & $\begin{array}{l}\text { Capecitabine+ } \\
\text { oxaliplatin+ } \\
\text { epirubicin+5FU }\end{array}$ & 52 & 15.8 \\
\hline $\mathrm{CE}$ & $\begin{array}{l}\text { Cyclophosphamide } \\
+ \text { epirubicin }\end{array}$ & 49 & 14.89 \\
\hline TAC & $\begin{array}{l}\text { Cyclophosphamide } \\
\text { + adriamycin+ } \\
\text { paclitaxel }\end{array}$ & 45 & 13.67 \\
\hline TCF & $\begin{array}{l}\text { Cisplatin+ } \\
\text { paclitaxel+ 5FU }\end{array}$ & 31 & 9.4 \\
\hline $\mathrm{GCa}$ & $\begin{array}{l}\text { gemicitabine+ } \\
\text { carboplatin }\end{array}$ & 31 & 9.4 \\
\hline $\mathrm{AC}$ & $\begin{array}{l}\text { Cyclophosphamide } \\
\text { +adriamycin }\end{array}$ & 22 & 6.68 \\
\hline Folfox & $\begin{array}{l}\text { Oxaliplatin+ } \\
\text { leucovorin+5FU }\end{array}$ & 21 & 6.38 \\
\hline $\mathrm{TCaF}$ & $\begin{array}{l}\text { Paclitaxel+ } \\
\text { carboplatin }+5 \mathrm{FU}\end{array}$ & 18 & 5.47 \\
\hline $\mathrm{CaT}$ & $\begin{array}{l}\text { Paclitaxel+ } \\
\text { carboplatin }\end{array}$ & 18 & 5.47 \\
\hline Capox & $\begin{array}{l}\text { Capecitabine + } \\
\text { Oxaliplatin }\end{array}$ & 12 & 5.31 \\
\hline T. Trans & $\begin{array}{l}\text { Paclitaxel+ } \\
\text { transtuzumab }\end{array}$ & 11 & 3.34 \\
\hline FEC & $\begin{array}{l}\text { Cyclophosphamide } \\
+ \text { epirubicin+ } 5 \mathrm{FU}\end{array}$ & 10 & 3.03 \\
\hline BEP & $\begin{array}{l}\text { Bleomycin }+ \\
\text { Etoposide }+ \\
\text { cisplatin }\end{array}$ & 9 & 2.73 \\
\hline
\end{tabular}

After the initiation of chemotherapy, it was observed that 92 patients $(88.46 \%)$, showed different types of adverse drug reaction during the study period. These 92 patients presented with 329 numbers of adverse drug reaction with female predominance with female to male ratio was 1.3:1. Majority of the patients showing ADRs were females 52 $(56.52 \%)$. Most common age group affected among these females were 51-60yrs (28.4\%). Among these 92 patients ,36\% presented with more than 4 ADRs, $25 \%$ with 3-4 ADRs and less than 3 ADRs were observed in $39 \%$ of the patients as shown in Figure 3. 


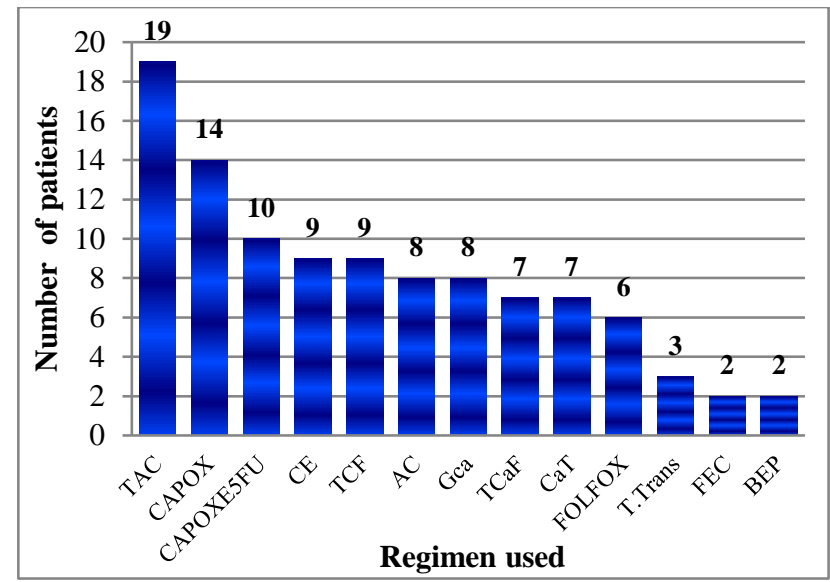

Figure 2: Cancer chemotherapy regimen used in study population.

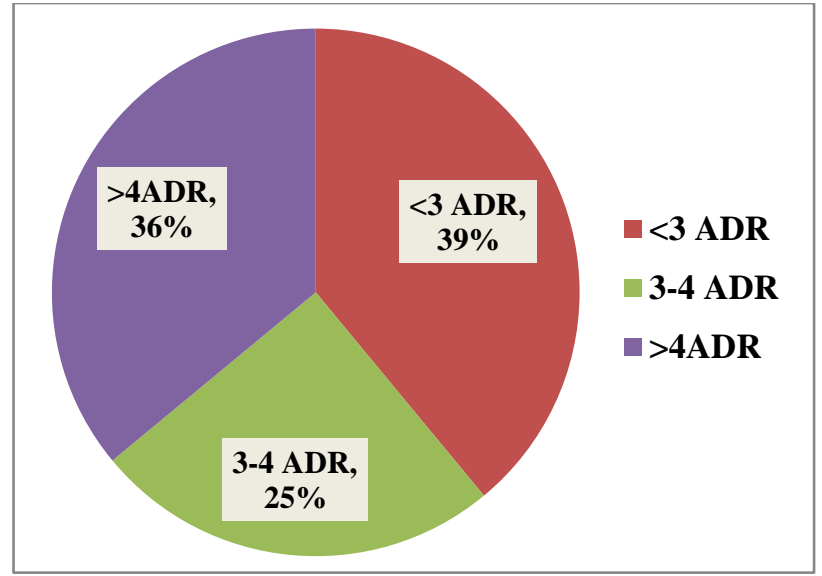

Figure 3: Incidence of adverse drug reaction.

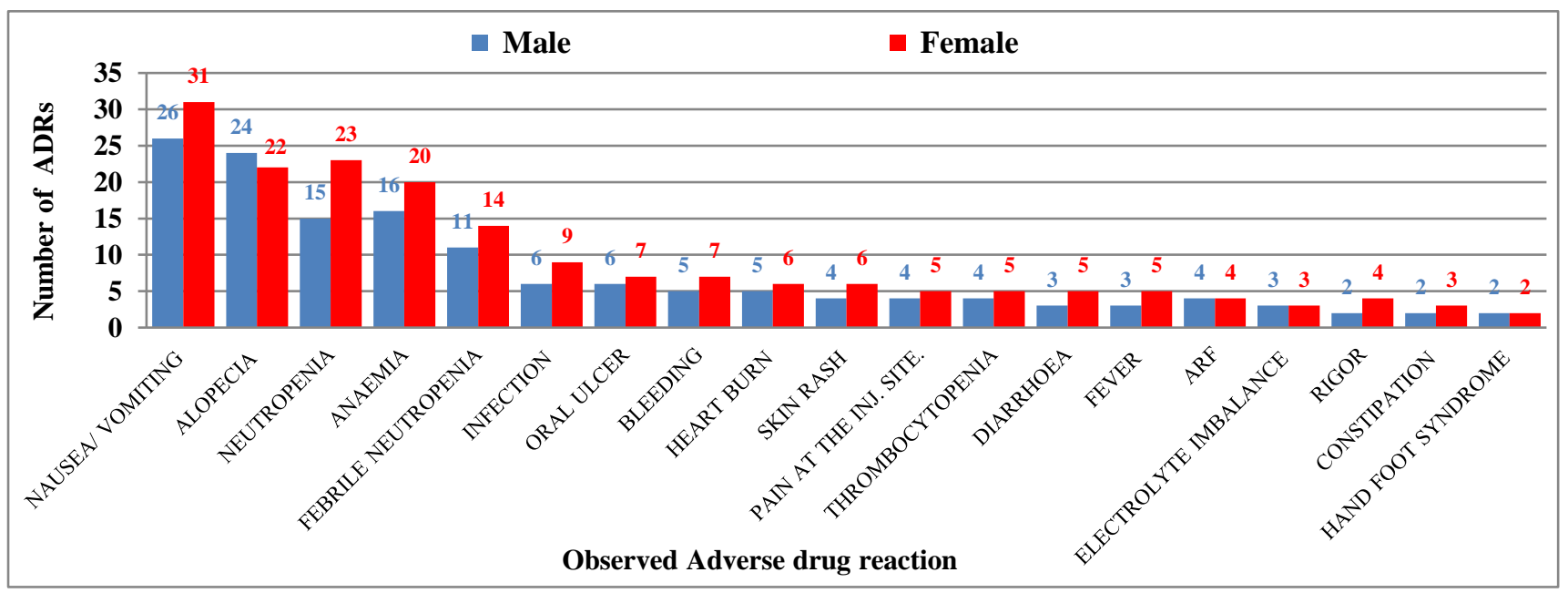

Figure 4: Observed adverse drug reaction (ADRs in male vs female).

Most common adverse drug reactions in our study were nausea and vomiting 57 (17.37\%), alopecia 46 (13.98\%), neutropenia $38(11.55 \%)$, anaemia $36(10.94 \%)$, febrile neutropenia $29(8.81 \%)$. ADRs due to oral ulceration and bleeding was $12(3.64 \%)$ each. Oral ulcer included glossitis, mucositis and angular stomatitis. Other adverse drug reactions like infections, heart burn, and pain at the injection site were also observed. Few ADRs of acute renal failure, rigor, electrolyte imbalance was also recorded. ADRs were most commonly seen with the haematological systems $(37.68 \%)$ followed by gastrointestinal system amounting $25.22 \%$ of the total ADRs. Haematological ADRs includes neutropenia, anaemia, febrile neutropenia, bleeding and thrombocytopenia. ADRs in gastrointestinal system included nausea/vomiting, heart burn, diarrhoea and constipation in decreasing order. Hand foot syndrome was observed in 4 patients only (Figure 4).

In the present study no single antineoplastic drug was prescribed. The most common regimen causing ADRs were Capoxe5FU (15.8\%), CE (14.89\%), TAC (13.67\%) and TCF (9.4\%). Platinum Compound (58.35\%), followed by antibiotics, antimetabolites, nitrogen mustard were the most common group of drugs causing different adverse drug reactions (Table 2). Platinum compounds include cisplatin, carboplatin and oxaliplatin. Antibiotics used in cancer chemotherapy include bleomycin, epirubicin and doxorubicin.

\section{Causality, severity and preventability assessment}

Causality assessment as per the WHO-UMC criteria in the present study showed that $225(68.38 \%)$ of the ADRs were probable and 104 (31.62\%) were possible. There was no certain ADR as rechallange was not attempted in any of the patient. The severity of the reported ADRs were assessed as per the modified Hartwig and Siegel Scale and it was observed that majority of the ADRs were moderate $228(69.31 \%)$ followed by mild in $67(20.36 \%)$. Severe ADRs were observed in 34(10.33\%) of the patients. As per the modified Schumock and Thorton scale, it was observed that majority $212(64.45 \%)$ of the ADRs were not 
preventable, $72(21.88 \%)$ were definitely preventable and $45(13.67 \%)$ were probably preventable (Table 3 ).

Table 3: Causality, severity and preventability assessment.

\begin{tabular}{|c|c|}
\hline \multicolumn{2}{|c|}{ Causality assessment as per the WHO- UMC criteria } \\
\hline Category & Number of ADRS $(n=329)$ \\
\hline Certain & Nil \\
\hline Probable & $225(68.38 \%)$ \\
\hline Possible & $104(31.62 \%)$ \\
\hline $\begin{array}{l}\text { Unlikely/unclassified/ } \\
\text { unassessible }\end{array}$ & Nil \\
\hline \multicolumn{2}{|c|}{$\begin{array}{l}\text { Severity assessment as per modified Hartwig and } \\
\text { Siegel scale }\end{array}$} \\
\hline Mild & $67(20.36 \%)$ \\
\hline Moderate & $228(69.31 \%)$ \\
\hline Severe & $34(10.33 \%)$ \\
\hline \multicolumn{2}{|c|}{$\begin{array}{l}\text { Preventability assessment as per Schumock and } \\
\text { Thorton scale }\end{array}$} \\
\hline Not preventable & $212(64.45 \%)$ \\
\hline Definitely preventable & $72(21.88 \%)$ \\
\hline Probably preventable & $45(13.67 \%)$ \\
\hline
\end{tabular}

In our study, it was observed that premedication was given to all patients receiving cancer chemotherapy. In spite of premedication 92 patients showed different ADRs. All were given $5 \mathrm{HT}_{3}$ antagonists like ondansetron, palonosetron to prevent chemotherapy induced nausea and vomiting. To prevent hyperacidity, gastritis, and heart burn 55 patients received $\mathrm{H}_{2}$ blocker like ranitidine and 37 patients received proton pump inhibitors like pantoprazole, rabeprazole. Thirty two patients, those who had previous history of nausea and vomiting in previous cycle given dexamethasone. 7 refractory cases of CINV were also reported, who were given combination of ondansetron, dexamethasone and apprepitant (Table 4).

Table 4: Premedications used among the study populations.

\begin{tabular}{|ll|}
\hline Premedications given & No of patients with ADRS \\
\hline Ondansetran $(8 \mathrm{mg})$ & 42 \\
\hline Ondansetran $(16 \mathrm{mg})$ & 32 \\
\hline Palonosetran $(0.25 \mathrm{mg})$ & 18 \\
\hline Pantoprazole $(40)$ & 16 \\
\hline Rabeprazole (20) & 21 \\
\hline Ranitidine (300) & 55 \\
\hline Dexamethasone (8mg) & 20 \\
\hline Dexamethasone (16mg) & 12 \\
\hline Apprepitant (125mg) & 7 \\
\hline
\end{tabular}

\section{DISCUSSION}

In the present study, adverse drug reactions following different cancer chemotherapy regimens in AHRCC, ODISHA was evaluated. Among those 104 patients enrolled for the study, 92 patients $(88.46 \%)$ showed adverse drug reactions which is similar to studies by Saini et al, and Prasad et al, i.e. $87.36 \%$ and $86.53 \%$ respectively. ${ }^{15,16}$ This finding is contrast to the observation by Malik et al, Goyal et al, and Swati B et al, which showed that the incidence of ADR in their study was $42 \%, 70 \%$ and $78 \%$ respectively. ${ }^{17-19}$

In the present study majority of the ADRs were observed in females $(56.52 \%)$ though no statistically significant difference was observed. This finding is consistent with study of Sharma et al, and other studies. ${ }^{20-22}$ A review of 48 cohort studies in UK showed that ADRs are more commonly observed in females than males, which was attributed to increased consulting rates for women compared to men in these studies. ${ }^{23}$ This is in contrast to the study by Prasad et al, Malik et al, and Bellare et al, where ADRs were more observed in male patients. ${ }^{16,17,24}$ More number of ADRs were observed in females due to alternation in pharmacokinetics and pharmacodynamic of the drug due to hormonal changes. ${ }^{25,26}$

Most of the ADRs were observed in age group 51-60yrs which is similar to studies by Prasad et al, Sharma et al. ${ }^{16,20}$ This may be due to the decrease metabolizing capacity and the excretory functions leading to accumulation of drugs in the body and thus increasing the risk of ADRs. ${ }^{27,28}$ This is in contrast to studies by Poddar et al, and Chopra et al, in which commonest age group was found to be 4150 yrs. $^{21,29}$

In our study it was observed that most common cancer presented at AHRCC during the study period was carcinoma of breast (29.8\%). This is similar to studies by Poddar et al, Kaur et al, and Chopra et al, which showed incidence of carcinoma of breast in 20\%, 20\% and 32.5\% of the patients respectively. ${ }^{21,28,29}$ Study by Sharma et al, shows non hodgkins lymphoma was the commonest in their study and bronchogenic carcinoma was commonest in a study by Prasad et al. ${ }^{16,20}$

In our study most of the adverse drug reactions were observed affecting the haematological system followed by gastrointestinal system. ADRs observed in the haematological system were neutropenia, anemia, febrile neutropenia, bleeding and thrombocytopenia. These findings were quite similar to the study of Mallik et al. ${ }^{17}$ Contrary to the present study Chopra et al, observed that adverse drug reaction affecting the gastrointestinal system was common followed by the haematological system. ${ }^{29}$

Commonest ADR was found to be nausea and vomiting $(17.37 \%)$ followed by alopecia (13.98\%), neutropenia $(11.55 \%)$ and anaemia $(10.94 \%)$. These findings are similar to studies by Prasad et al, Swathi et al, and Chopra et al, which show incidence of nausea and vomiting was $33.33 \%, 45 \%$ and $25.5 \%$ respectively. ${ }^{16,19,29}$ But studies by Poddar et al, Kaur, G. Laxmi et al, showed alopecia being the most common adverse drug reaction was observed in $58 \%, 27.76 \%, 95 \%$ of the total ADRs respectively. ${ }^{21,28,30}$ 
Most of the patients with nausea and vomiting were managed with $5 \mathrm{HT}_{3}$ antagonists in increased doses. This finding is consistent with other studies. ${ }^{17,21,29}$ Seven refractory cases of chemotherapy induced nausea and vomiting needed combination of ondansetron, dexamethasone and apprepitant which is similar to studies of Kirthi et al. ${ }^{31}$ Drugs taken for management of ADRs were also observed and those include growth colony stimulating factor like filgrastim, tranexamic acid for bleeding, antibiotics like ceftriaxone, ciprofloxacin, metronidazole, clotrimazole mouth paint, fluconazole, antihistaminics, NSAIDS like tramadol, paracetamol, multivitamins, antidiarrhoeals etc. This finding is also similar to other study. ${ }^{31}$

In our study platinum compounds which include cisplatin, carboplastin and oxaliplatin were found to be the most common cause of adverse drug reactions ie.43.46\% followed by antibiotics. Many studies showed that platinum compounds are the most common antineoplastic drug causing adverse drug reaction. ${ }^{16,20,28,29,31,32}$ Antimetabolites and alkylating agents were found to be the commonest antineoplastic drugs in a study by Poddar et al. $^{21}$

Causality assessment as per the WHO UMC scale shows $68.38 \%$ of the ADRs were probable and $31.62 \%$ were possible. No certain reaction was observed as no rechallenge was done. This finding was similar to other studies. ${ }^{15,19,20}$ In contrast most of the ADRs were possible in a study by Chopra et al. ${ }^{29}$ As per the modified Hartwig and Siegel Scale $69.31 \%$ of the ADRs were moderate which is comparable to the other studies. ${ }^{19,20}$ Study by Chopra et al, showed in their study that most of the ADRs were mild in nature. ${ }^{29}$ As per modified Shamrock and Thorton scale $64.45 \%$ of the ADRs are not preventable this is similar to another study. ${ }^{20}$

\section{Limitation}

Though the present study is the first from Regional Cancer Centre, Odisha, it has certain limitations like short duration of the study, unicentric in nature, less number of ADRs for analysis. Since all the patients were on multiple drug regimens, it was difficult to correlate any particular ADR due to a definite drug.

\section{CONCLUSION}

The analysis of the adverse drug reactions with assessment of causality, severity and preventability showed the importance of Pharmacovigilance in cancer chemotherapy. Chemotherapy regimens are very often complicated and adverse drug reactions to them are lot. Many a times ADRs are misdiagnosed and underreported. Pharmacovigilance in oncology department is highly essential for safe and effective medications. Regular and sustained monitoring with due care and reporting will decrease the occurrence of ADRs, increase patient compliance, reduce morbidity and mortality, so also financial burden for the patients and society. Creating awareness among the treating physicians and training of the health care personnel will definitely help in the early diagnosis of adverse drug reactions and their prompt management.

\section{Funding: No funding sources}

Conflict of interest: None declared

Ethical approval: The study was approved by the Institutional Ethics Committee of S.C.B. Medical College, Cuttack

\section{REFERENCES}

1. Warnakulasuriya S. Global epidemiology of oral and oropharyngeal cancer, Oral Oncol. 2009;45(4):30916. Available at: http://www.oraloncology.com /article/ S1368-8375(08) 001838/fulltext

2. Mariotto AB, Yabroff KR, Shao Y, Feuer EJ, Brown ML. Projections of the cost of cancer care in the United States: 2010-2020. J Natl Cancer Inst. 2011;103:117-28.

3. NCRP: Three year report of population based cancer registries: 2012-2014 National Cancer Registry Programme (Indian Council of Medical Research), Bangalore, 2016. Available at: www.ncrpindia.org.

4. Chabner BA, Amrein PC, Druker BJ. Antineoplastic agents.In: Bruntan LL, Lazo JS, Parker KL, editors. Goodman and Gilman's The Pharmacological Basis of Therapeutics. $11^{\text {th }}$ Ed USA: McGraw-Hill Companies, Inc.; 2006:1315.

5. Edward IR. Pharmacological basis of adverse drug reactions. In: Speight TM, Holford NHG, editors. Avery's Drug Treatment. Chapter 9. Auckland: Adis International limited; 1997:1852.

6. Hurwitz N, Wade OL. Intensive hospital monitoring of adverse reactions to drugs. $\mathrm{Br}$ Med $\mathrm{J}$. 1969;1(5643):531-6.5.

7. Pirmohamed M, James S, Meakin S, Green C, Scott AK, Walley TJ, et al. Adverse drug reactions as cause of admission to hospital: Prospective analysis of 18 820 patients. BMJ. 2004;329:15-9.

8. Gandhi TK, Bartel SB, Shulman LN, Verrier D, Burdick E, Cleary A, et al. Medication safety in the ambulatory chemotherapy setting. Cancer. 2005 Dec 1;104(11):2477-83.

9. Lau PM, Stewart K, Dooley M. The ten most common adverse drug reactions (ADRs) in oncology patients: do they matter to you? Support. Care Cancer. 2004;12(9):626-33.

10. Niraula S, Seruga B, Ocana A, Shao T, Goldstein R, Tannock IF, et al. The price we pay for progress: A meta-analysis of harms of newly approved anticancer drugs. J Clin Oncol. 2012;30:3012-9.

11. Kshirsagar NA, Karande SC, Potkar CN. Adverse drug reaction monitoring in India. $\mathrm{J}$ Assoc Physicians India. 1993;41:374-6.

12. WHO-UMC standardized case causality assessment. 2011. Available at: http://who umc.org/Graphics/24734.pdf. 
13. Hartwig SC, Siegel J, Schneider PJ. Preventability and severity assessment in reporting adverse drug reactions, Am J Hosp Pharm. 1992;49:2229-32.

14. Schumock GT, Thornton JP. Focusing on the preventability of adverse drug reactions. Hospital pharmacy. 1992 Jun;27(6):538.

15. Saini V, Medhi B, Sewal R, Ahmad Y. Prospective observational study of adverse drug reactions of anticancer drugs used in cancer treatment in a tertiary care hospital. Indian Journal of Pharmaceutical Sciences. 2015;77(6):687.

16. Prasad A, Datta PP, Bhattacharya J, Pattanayak C, Chauhan AS, Panda P. Pattern of adverse drug reactions due to cancer chemotherapy in a tertiary care teaching hospital in Eastern India. J Pharmacovigilance. 2013 Feb 8;1(2):107.

17. Mallik S, Palaian S, Ojha P, Mishra P. Pattern of adverse drug reactions due to cancer chemotherapy in a tertiary care teaching hospital in Nepal. Pak J Pharm Sci. 2007;20:214-8.

18. Goyal YN, Solanki KC, Mistry RA, Joshi ND, Singh AP, Gajera MV. Pattern of adverse drug reactions due to cancer chemotherapy in tertiary care teaching hospital in Gujarat. Int J Sci Res. 2014;3:333-5.

19. Swathi B, Bhavika D, Begum N. Adverse drug reaction profi les of commonly used platinum compounds in cancer chemotherapy. Int $\mathrm{J}$ Basic Clin Pharmacol. 2015;4:284-9.

20. Sharma A, Kumari KM, Manohar HD, Bairy KL, Thomas J. Pattern of adverse drug reactions due to cancer chemotherapy in a tertiary care hospital in South India. Perspect Clin Res. 2015;6:109-15.

21. Poddar S, Sultana R, Sultana R, Akbor MM, Azad MA, Hasnat A. Pattern of adverse drug reactions due to cancer chemotherapy in tertiary care teaching hospital in Bangladesh. Dhaka Univ J Pharm Sci. 2009;8:11-6.

22. Surendiran A, Balamurugan N, Gunaseelan K, Akhtar S, Reddy KS, Adithan C. Adverse drug reaction profile of cisplatin-based chemotherapy regimen in a tertiary care hospital in India: An evaluative study. Indian J Pharmacol. 2010;42(1):40-3.

23. Martin RM, Biswas PN, Freemantle SN, Pearce GL, Mann RD. Age and sex distribution of suspected adverse drug reactions to newly marketed drugs in general practice in England: analysis of 48 cohort studies. Br J Clin Pharmacol. 1998;46(5):505-11.
24. Bellare PS, Ashwin K, Pu SP, Vinaykumar S, Kb R. A Retrospective Evaluation of Adverse Drug Reactions Due to Cancer Chemotherapy in a Tertiary Care Hospital in South India. Journal of Young Pharmacists. 2016Jan;8(3):251-4.

25. Soldin OP, Chung SH, Mattison DR. Sex differences in drug disposition. J Biomed Biotechnol. 2011:187103.

26. Gandhi M, Aweeka F, Greenblatt RM, Blaschke TF. Sex differences in pharmacokinetics and pharmacodynamics. Annu Rev Pharmacol Toxicol. 2004;44:499-523.

27. Hanlon JT, Ruby CM, Artz M. Geriatrics. In: Di Piro JT, Talbert RL, Yee GC, Matzke GR, Wells BG, Posey LM, editors. Pharmacotherapy A Pathophysiologic Approach. 5 $5^{\text {th }}$ Ed. New York: McGraw Hill Inc.; 2002:79-89.

28. Kaur K, Sood M, Bhagat S, Singh T, Jain M, Arora D, et al. Spontaneous adverse drug reaction monitoring in oncology: Our experience. Indian Journal of Cancer. 2015;52(3):467.

29. Chopra D, Rehan HS, Sharma V, Mishra R. Chemotherapy-induced adverse drug reactions in oncology patients: A prospective observational survey. Indian J Med Paediatric Oncol. 2016;37:42-6.

30. Lakshmi Durga G, Sivaramakrishna TV, Ramya A, Mounika S, Anusha G. Medication Utilization in Incident Adverse Drug Reactions of Cancer Chemotherapy in a Tertiary Care Hospital Jour of Pharm and Bio Sci. Mar -Apr 2015;10(2):05-9.

31. Kirthi C, Afzal A, Reddy M, Ali SA, Yerramilli A, Sharma S. A studyon the adverse effects of anticancer drugs in an oncology center of a tertiary care hospital. Int J Pharm Pharm Sci. 2014;6:580-3.

32. De A. Monitoring of suspected adverse drug reactions in oncology unit of an urban multi speciality teaching hospital. Int J Res Pharm Biomed Sci (online). 2010;1:1-32.

Cite this article as: Rout A, Panda RK, Mishra V, Parida P, Mohanty S. Pharmacovigilance in cancer chemotherapy in regional cancer center of Eastern India: prospective observational study. Int J Basic Clin Pharmacol 2017;6:1910-6. 